\title{
A Study of Mechanical Properties and Wear Resistance of Pure Aluminium / TZ-3Y20A Composites
}

\author{
N.A.Mansour', A.A.Hassan ${ }^{2}$, O.H.Ibrahim ${ }^{3}$ A.F.waheed ${ }^{4}$ \\ Metallurgy Department, Nuclear Research Center, Egyptian Atomic Energy Authority, Cairo, Egypt
}

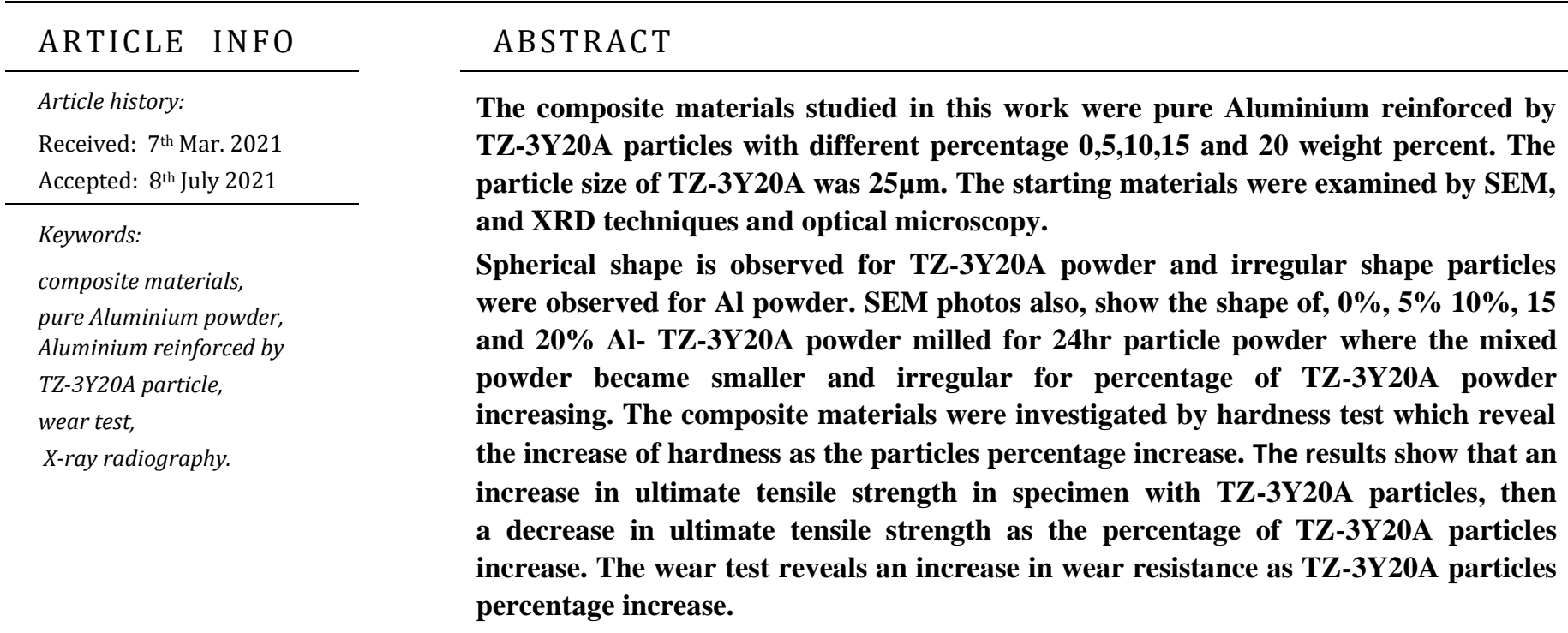

\section{INTRODUCTION}

Metal-Matrix composites are promising in enhancing mechanical properties such as hardness, young's modulus, 0.2 yield strength and ultimate tensile strength due to the presence of nano-or micro sized particles reinforcement in the matrix. Regardingthe mechanical properties, the reinforcement results in high strength and hardness, at the expense of some ductility (1). These alloys are widely used for high performance applications, because of their improved physical and mechanical properties (2).

It has been reported that the abrasive wear resistance of particle reinforced metal/matrix changes with the volume fraction of particles, in both cases of both high and low stress abrasive wear conditions (3). Additional functions can have added into some metal / matrix through appropriate selection of constituents. For example, metal matrix with $\mathrm{B}_{4} \mathrm{C}$ reinforcement provides a high neutron for neutron containment (4). The mechanical and wear properties of composite materials are governed by selection of type, volume fraction of reinforcement and its compatibility with metallic matrix during materials processing (5). A. Mazahiery et al (6) have conducted a study of the effect of $\mathrm{Al}$ and $\mathrm{Al}_{2} \mathrm{O}_{3}$ particulates in nano-scale on properties of aluminium, such as hardness, elastic modulus, structure and wear properties.

The aim of present work is to investigate the mechanical and wear behavior of composites fabricated from pure aluminium mixed with TZ-3Y20A [(Zro2+3 $\mathrm{mol} \% \mathrm{Y} 2 \mathrm{O} 3)+20 \% \mathrm{Al} 2 \mathrm{O} 3]$ in $0,5,10,15$ and 20 weight $\%$

\section{EXPERIMENTAL WORK}

\subsection{Materials and Test procedures}

A mixture of high purity Aluminium (99.9\%) and highly pure TZ-3Y20A powder of an average particle size $(25 \mu \mathrm{m})$ mixed with different weight percentages $(0,5,10,15$ and 20) was prepared. The different percentage mixtures were milled in ball mill for 24 hours at $50 \mathrm{rpm}$ speed. The different compositions were subjected to cold pressing at 20 tons. After pressing process, the compacts were sintered at $700^{\circ} \mathrm{C}$ for $1 \mathrm{hr}$ in muffle furnace (carbolite furnace, GPC 1300, UK) in 
inert gas (Argon), with heating rate $50^{\circ} \mathrm{C} / \mathrm{min}$, at the end of heating cycles specimens were cooled to room temperature.

X-ray diffractometer (XRD - 3A, Shimatzu-Japan, $\mathrm{CuK} \alpha-\mathrm{Ni}$ filter) was used for phase analysis of the composites. Also, Optical Microscope and SEM were used for investigating the morphology of the composites.

For investigating the mechanical properties of the composites, wire cutting machine was used to fabricate the specimens. Instron tensile machine was used for testing the mechanical behavior of the composites.

The ware resistance test was also investigated using abrasive wear test in air under dry condition and at room temperature, the applied load was 340 gm giving a normal constant pressure of $0.25 \mathrm{MP}$, the disk speed was $150 \mathrm{rpm}$, the test duration $15 \mathrm{~min}$. The fracture surface after tensile test was examined by SEM. The wear surface of the compacts was examined by optical microscopy.

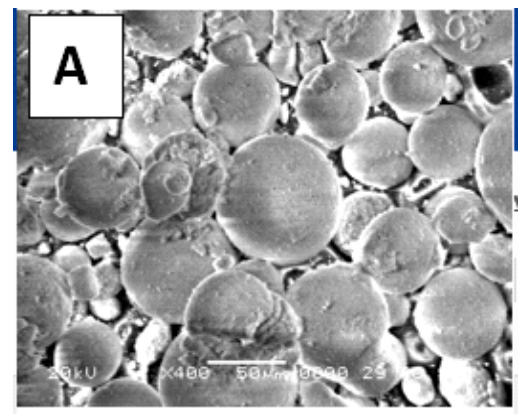

\section{RESULTS AND DISCUSSION}

\subsection{Microstructure}

SEM photos show the shape of as received Al-TZ-3Y20A powder and Aluminium powder. Spherical shape was observed for TZ-3Y20A powder and irregular shape particles were observed for Al powder as shown in Figures (1-a, and 1-b). SEM photos also, show the shape of $0 \%, 5 \% 10 \%, 15$ and $20 \%$ Al- TZ-3Y20A powder milled for $24 \mathrm{hr}$ particle powder as shown in Figure (2). It can be observed that as percentage of TZ-3Y20A powder increases, the particle size of the mixed powder became smaller and irregular (Figures 2-b-2E). As a result, fragmented welded metal particles were generated and the result is the formation of a real composite particle. As welding is a predominate mechanism in the process, the particles change their morphology by pilling up the laminate particles. These phenomena, deformation, welding and solid dispersion harden the material and increase the fracture process, which also contributes to equiaxed morphology (7).

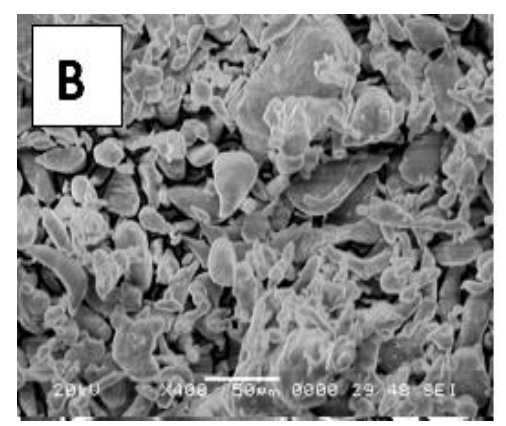

Fig. (1): a) The SEM of as received TZ-3y20A powder

b) The SEM of as received Aluminium powder
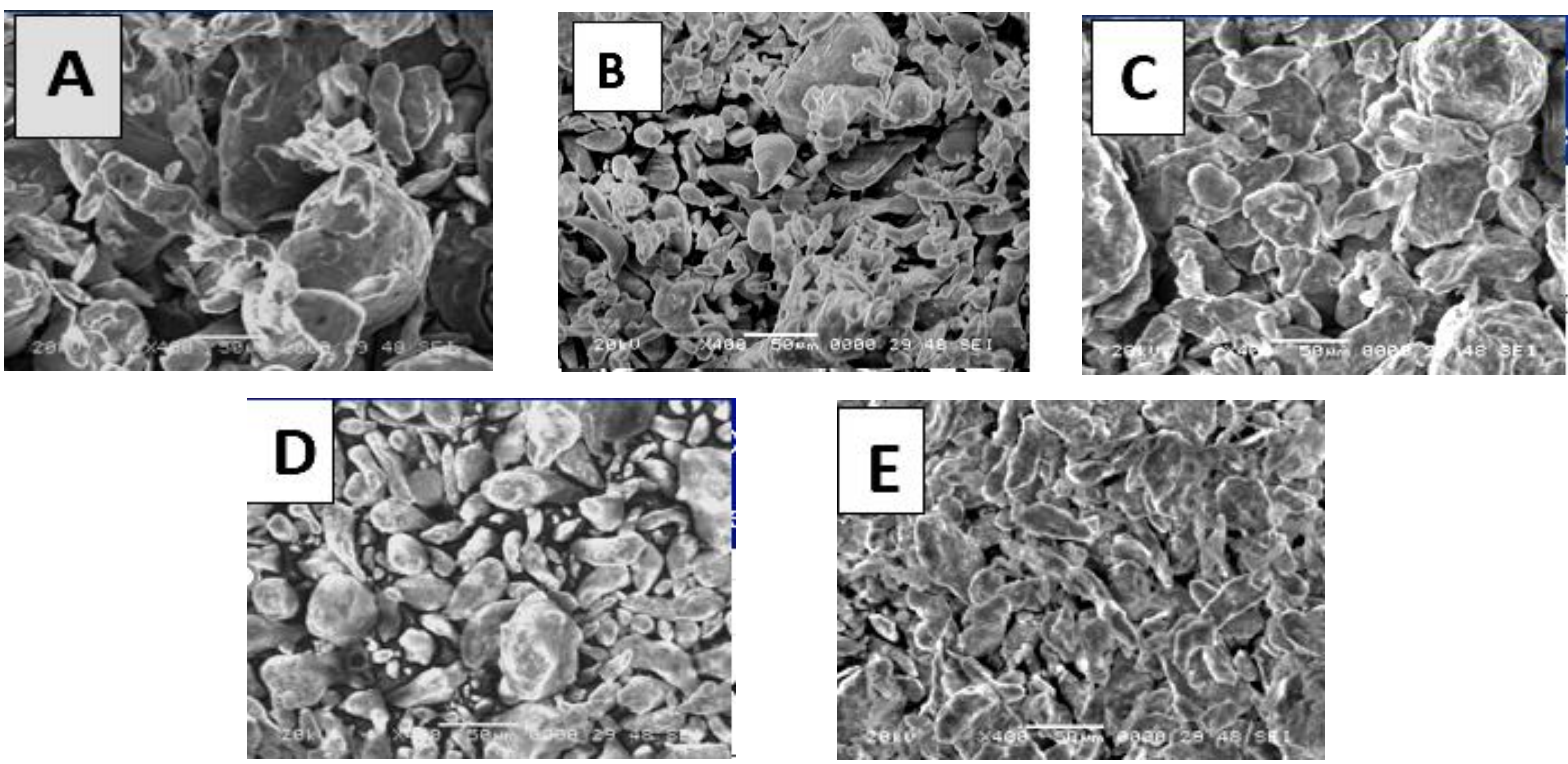

Fig. (2): The SEM of powder mixtures milled for $24 \mathrm{hr}$
(a) Pure Aluminium powder
(b) Al-5\% TZ-3Y20A powder
(c)Al- 10\% TZ-3Y20A powder
(d) Al- 15\% TZ-3Y20A powder

(e) Al-20\% TZ-3Y20A powder 
The XRD pattern shows the effect of increasing the TZ-3Y20A percentage in Al-powder on the phase. A new peak at 2 theta equal 30 was observed by the increasing the TZ-3Y2OA content which is about $20 \%$, the new peak was growing and become observed as shown in Fig. (3). This new peak was due to the increase in TZ-3Y20A percentage.

Pure Al power

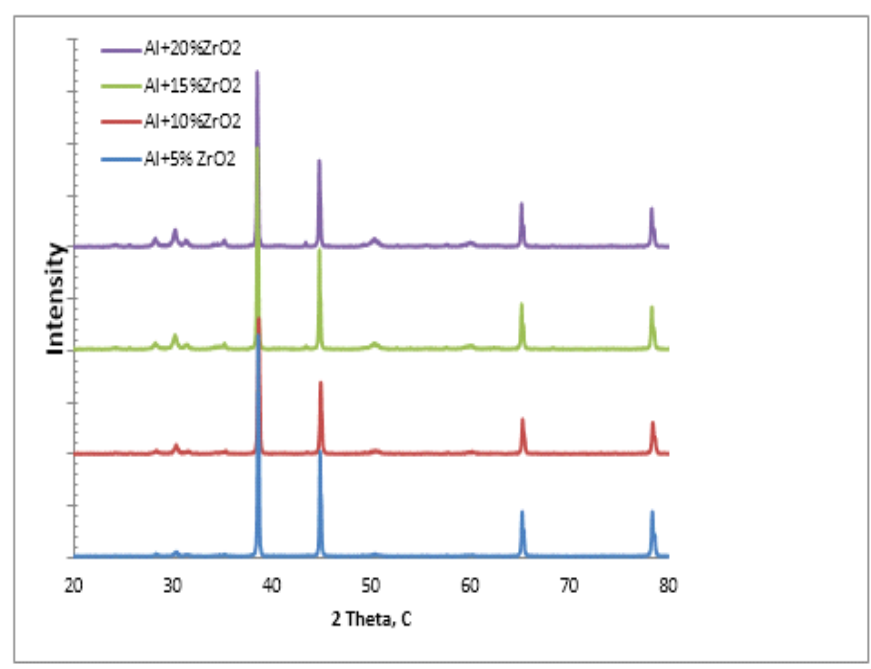

Fig. (3): The XRD patterns of powder mixtures milled for 24 hr, 5\% TZ-3Y20A, 10\% TZ-3Y20A, 15\% TZ3Y20A, and 20\% TZ-3Y20A
It is also observed in figure (3) the XRD pattern high peaks are for 5\% TZ-3Y20A, 10\% TZ-3Y20A, 15\% TZ$3 \mathrm{Y} 20 \mathrm{~A}$, and $20 \%$ TZ-3Y20A powder at $2 \theta=38,45,65$ and 80 .

Pure Al

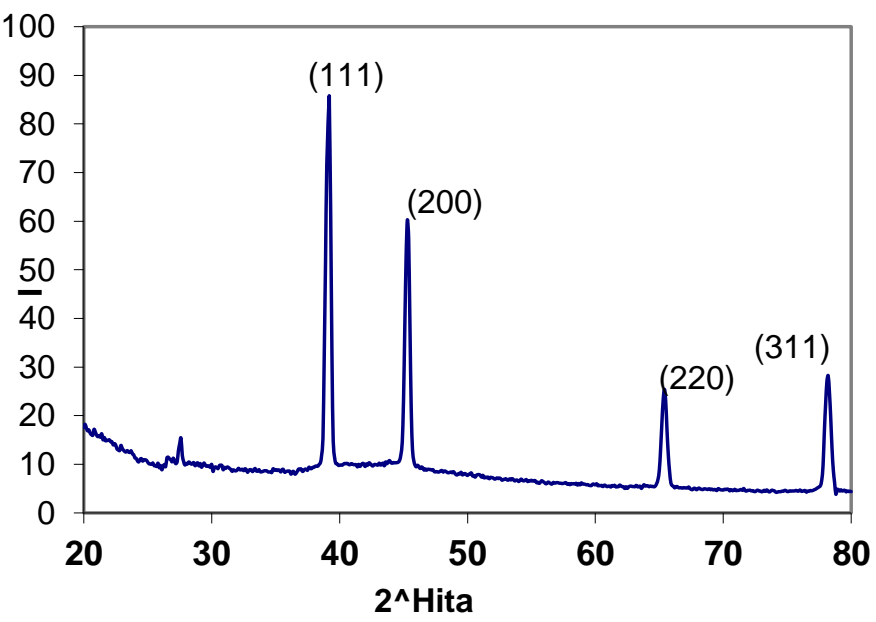

Fig. (4): The XRD patterns of pure Al powder milled for $24 \mathrm{hr}$

SEM was used for investigating the effect of the milling time for different powder compositions.

Increasing the TZ-3Y20A percentage in $\mathrm{Al}$ powder, more coated particles of TZ-3Y20A particles by aluminium are shown as in Fig. (5).
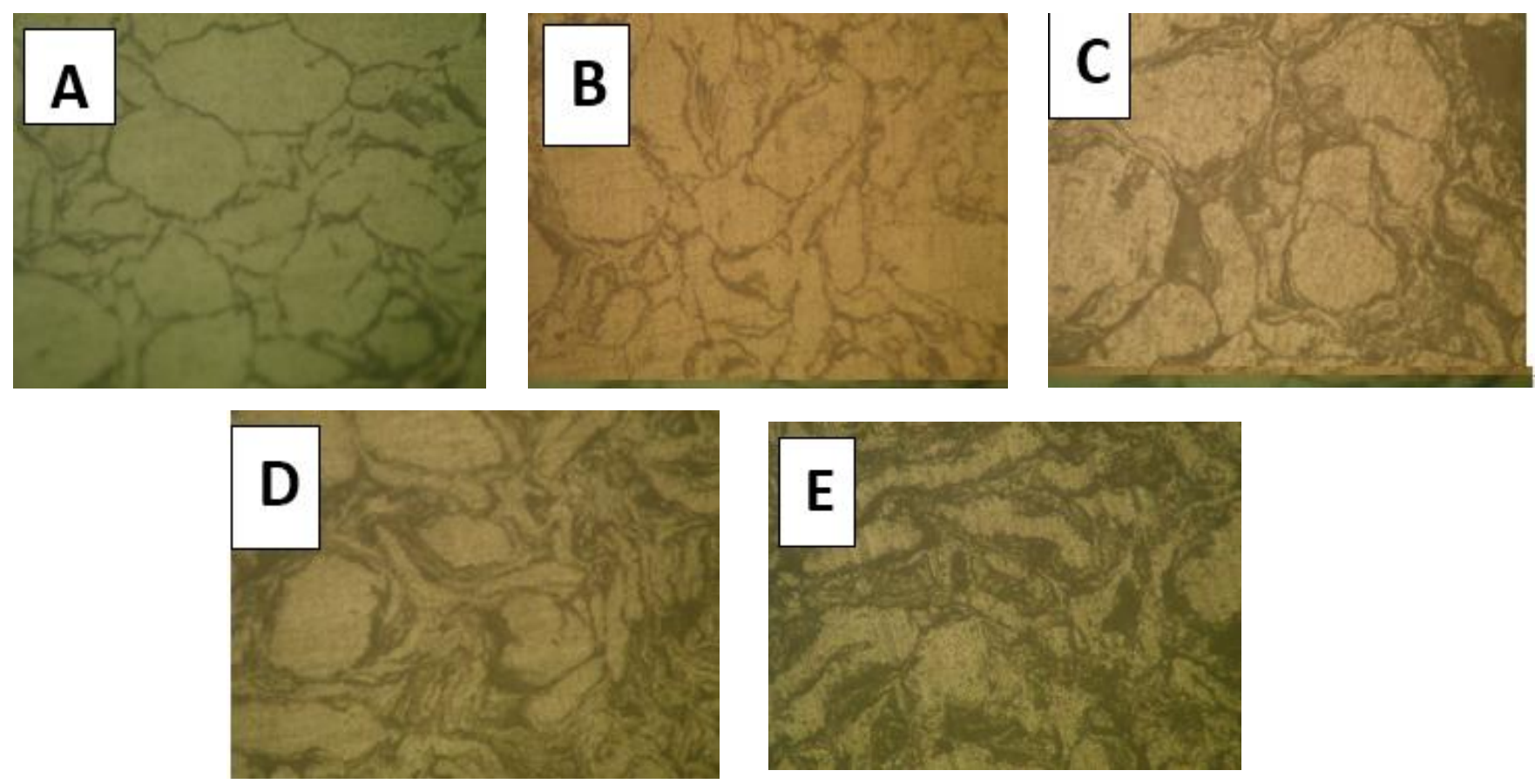

Fig. (5): The Optical micrograph of powder mixtures milled for $24 \mathrm{hr}$
(A) Optical Micrograph of pure Al
(B) Optical Micrograph of 5\% TZ-3Y20A Sample
(C) Optical Micrograph of $10 \%$ TZ-3Y20A Sample
(D) Optical Micrograph of $15 \%$ TZ-3Y20A,
(E) Optical Micrograph of $20 \%$ TZ-3Y20A 


\subsection{Mechanical behavior}

\subsubsection{Tensile Test Results}

Tensile test specimens with, sectional area $4 \times 1 \mathrm{~mm}$ and $20 \mathrm{~mm}$ gauge length (as shown in Fig. 6), were made using wire cutting machine. Fig.(7-a-d) shows the tensile test results of pure $\mathrm{Al}$ and $\mathrm{Al} / \mathrm{TZ}-3 \mathrm{Y} 20 \mathrm{~A}$ composites with different percentages of TZ-3Y20A powder.

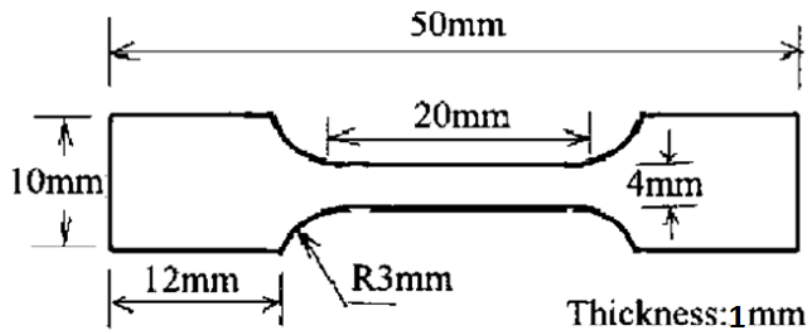

Fig. (6): Shape of the tensile test sample

The results of the tensile test of the Al-TZ-3Y20A composites are shown in Fig. (6 a-e). It is observed that the ultimate tensile strength increases to $91 \mathrm{Mpa}$ with addition of 5\% TZ-3Y20A, then the value of the ultimate tensile strength slightly decreases with more addition of the fine particles ofTZ-3Y20A. It becomes $52 \mathrm{Mpa}$ in case of $20 \%$ TZ-3Y20A.

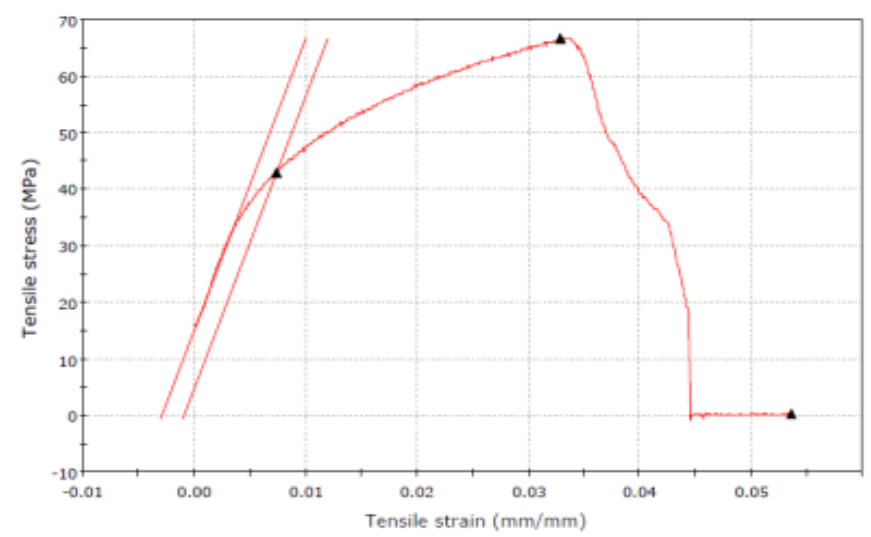

(a) Pure- Al sample

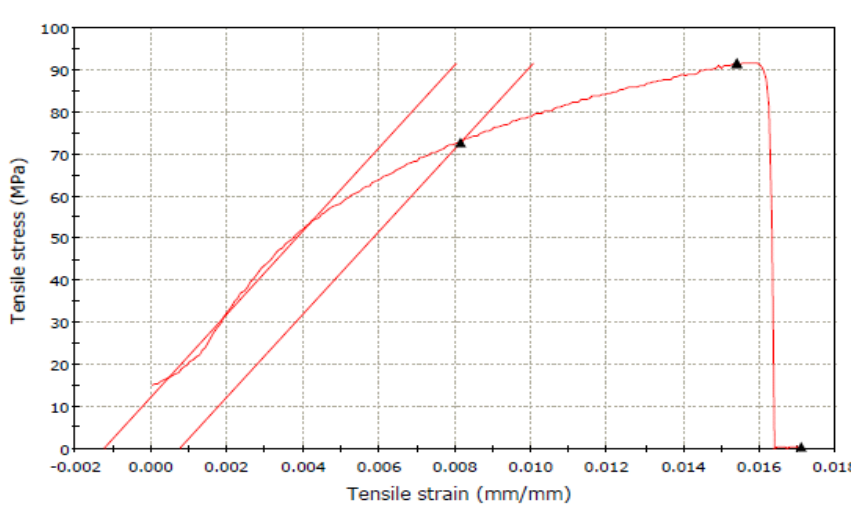

(b) Al- $5 \%$ TZ-3y20A

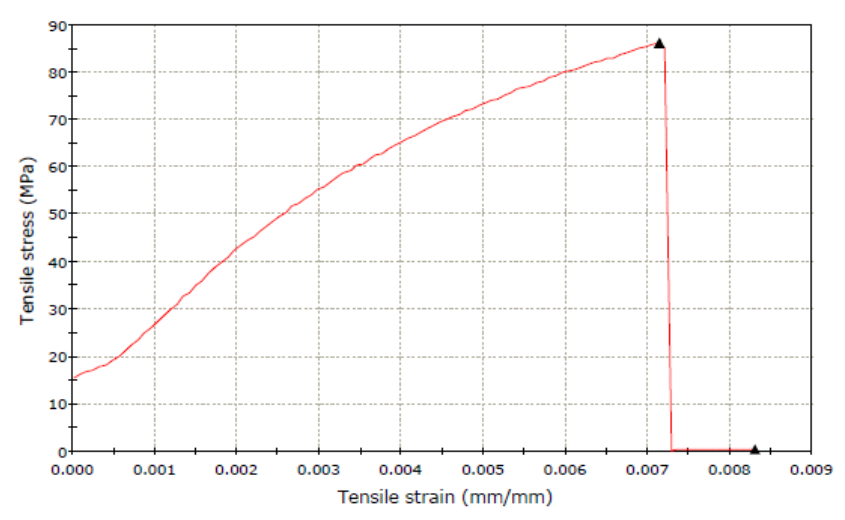

(c) Al-10 \% TZ-3y20A

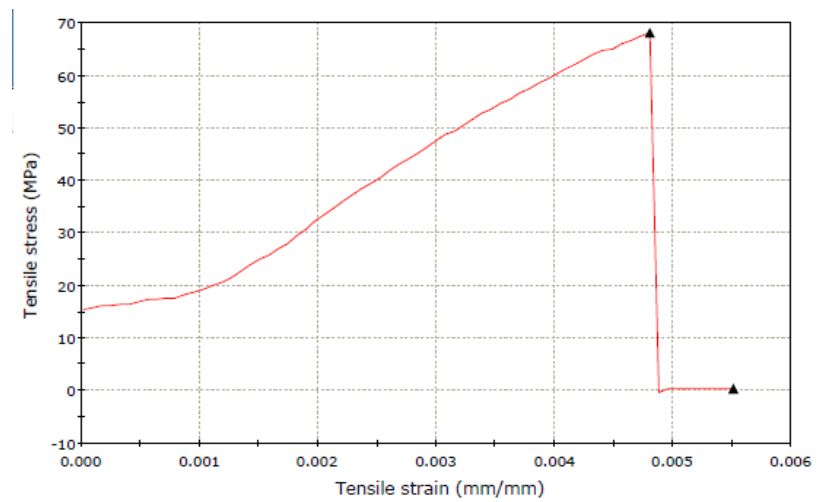

(d) Al- $15 \%$ TZ-3y20A

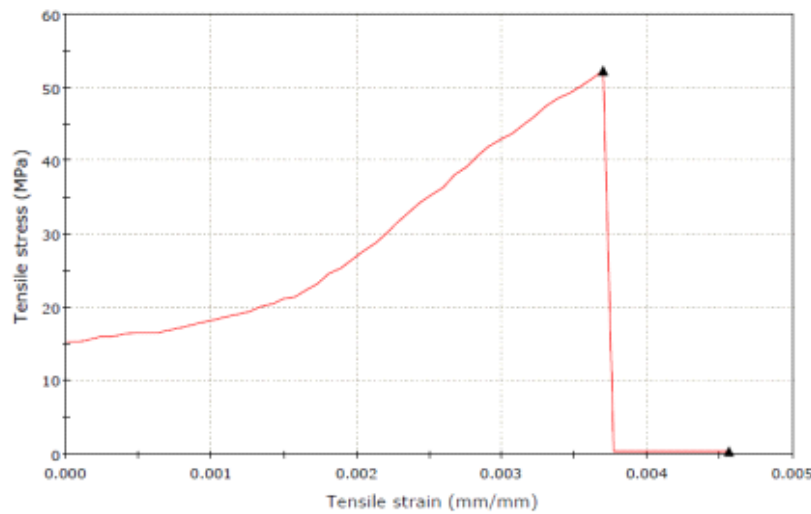

(e) Al- $20 \%$ TZ-3y20A

Fig. (7): Tensile test results of $\mathrm{Al} / \mathrm{TZ}-3 \mathrm{y} 20 \mathrm{~A}$ composites with different TZ-3y20A percentages:
(a) Pure Al,
(b) $\mathrm{Al} / 5 \% \mathrm{TZ}-3 \mathrm{y} 20 \mathrm{~A}$,
(c) $\mathrm{Al} / 10 \% \mathrm{TZ}-3 \mathrm{y} 20 \mathrm{~A}$,
(d) $\mathrm{Al} / 15 \% \mathrm{TZ}-3 \mathrm{y} 20 \mathrm{~A}$
(e) $\mathrm{Al} / 20 \% \mathrm{TZ}-3 \mathrm{y} 20 \mathrm{~A}$.

The effect of the powder composition on tensile strain at maximum load and the tensile strain at break \% is shown in Fig. (8). A severe decrease in the tensile strain up to $10 \% \mathrm{TZ}-3 \mathrm{Y} 20 \mathrm{~A}$ composition has occurred, after that, a slight decease is observed with increasing the TZ-3Y20A percentage 


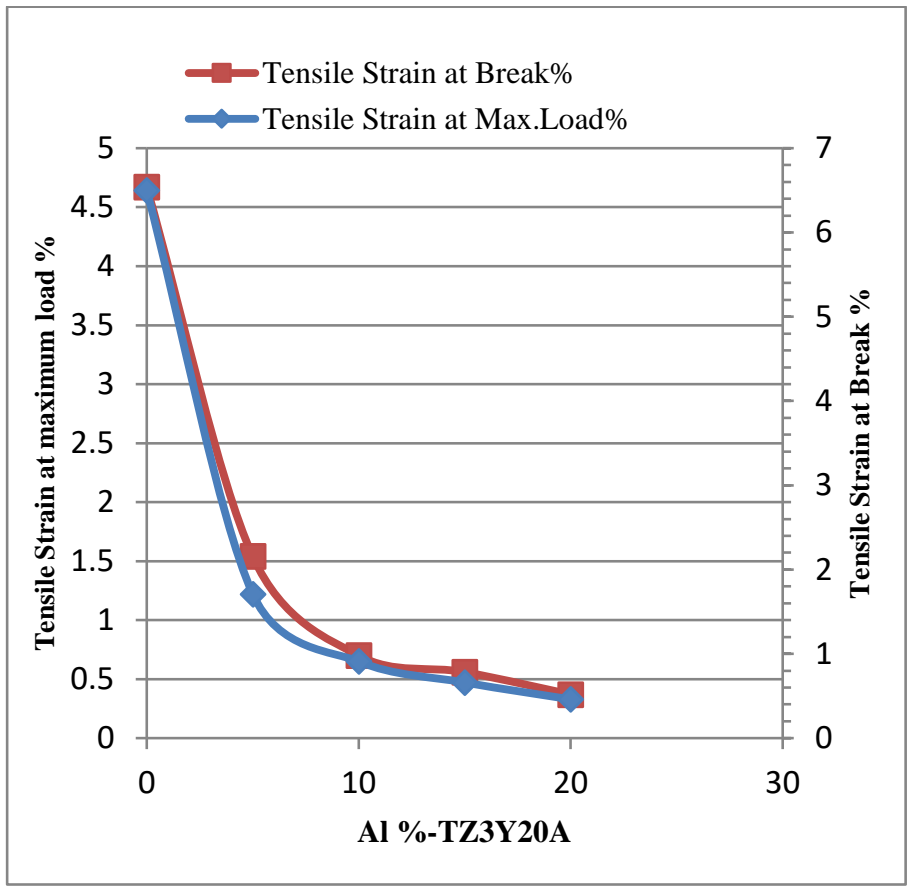

Fig. (8): The Effect of powder composition on Tensile Strain at maximum load (MPa), and Tensile Strain at maximum Break \%

The effect of the powder composition on the ultimate tensile strength is shown in Fig. (9). It is obvious that a slight increase in UTS with TZ-3Y20A occurred up to $5 \%$, after that, it decreased again due to the increase in TZ-3Y20A \%.

Fig. (9) reveals the decrease in the ultimate tensile strength as an effect of TZ-3Y20A particles addition. The increase in the ultimate tensile strength reached 5\% TZ-3Y20A as compared to pure Aluminium, this can be due to the multidirectional thermal stress at Al-TZ3 Y20A interface small particles, and the distribution of the particles $(9,10)$. The fine particles of TZ-3Y20A give the enhancement in the high strength of the composite as compared to pure Aluminium. Addition of $15 \% \mathrm{TZ}$ $3 Y 20 \mathrm{~A}$ led to increasing the strength to $85 \mathrm{Mpa}$ increases, then it started to decrease on adding $20 \%$ TZ$3 \mathrm{Y} 20 \mathrm{~A}$, as compared to pure Aluminium. The decrease in the ultimate tensile strength as more particles than $5 \% \mathrm{TZ}-3 \mathrm{Y} 20 \mathrm{~A}$ were added can be due to high degree of defects. Increasinginterfaces between matrix and particles increases of dislocations which means increasing the effects around the particles, because of the difference in the thermal expansion coefficient of Aluminium and particles, this might result in disordering of interface and decrease the UTS in composite with increasing the volume fraction of particles (11).

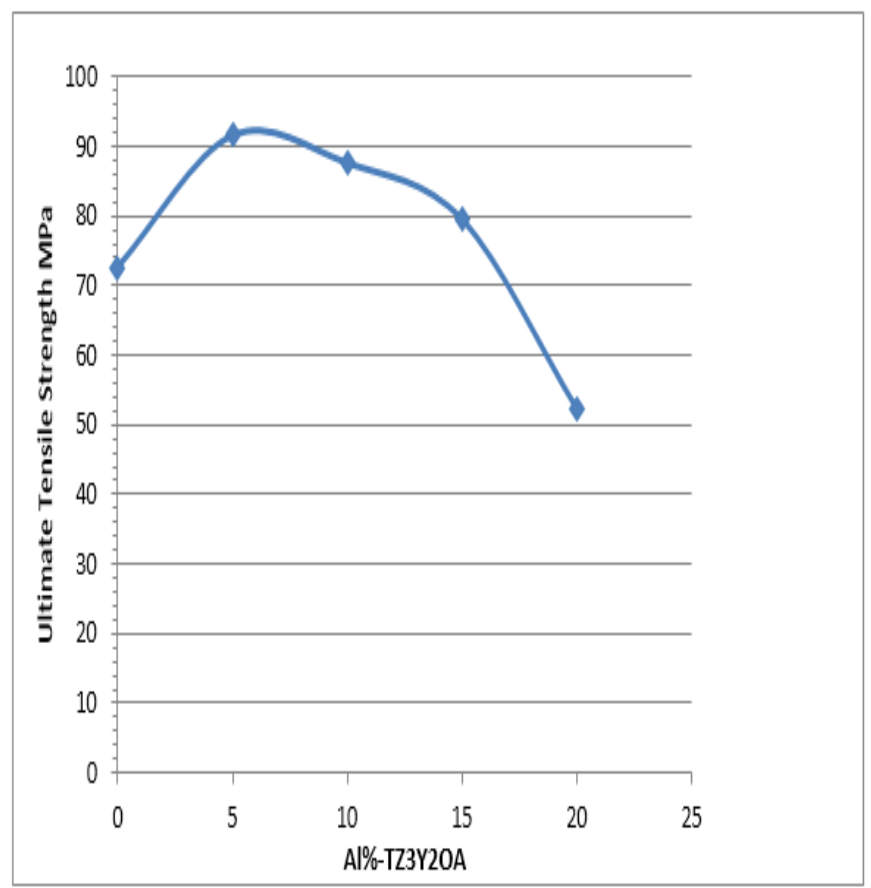

Fig. (9): The Effect of powder composition on the Ultimate Tensile Strength (MPa)

\subsubsection{Micro-hardness test results}

Figure (10) shows the micro-hardness of compacts as a function of the TZ-3Y20A content. The curve reveals an increase in micro-hardness as the content of the TZ$3 Y 20 A$ particles increases. The increase in microhardness of the reinforced Al/TZ-3Y20A compacts can be attributed to: (a) A good uniform distribution of the hard TZ-3Y20A particles in soft Aluminium matrix. (b) Reinforcement of grain structure in the Aluminium matrix. (c) A higher constraint to localized matrix deformation during induction due to the presence of lowered coefficient of thermal expansion (8).

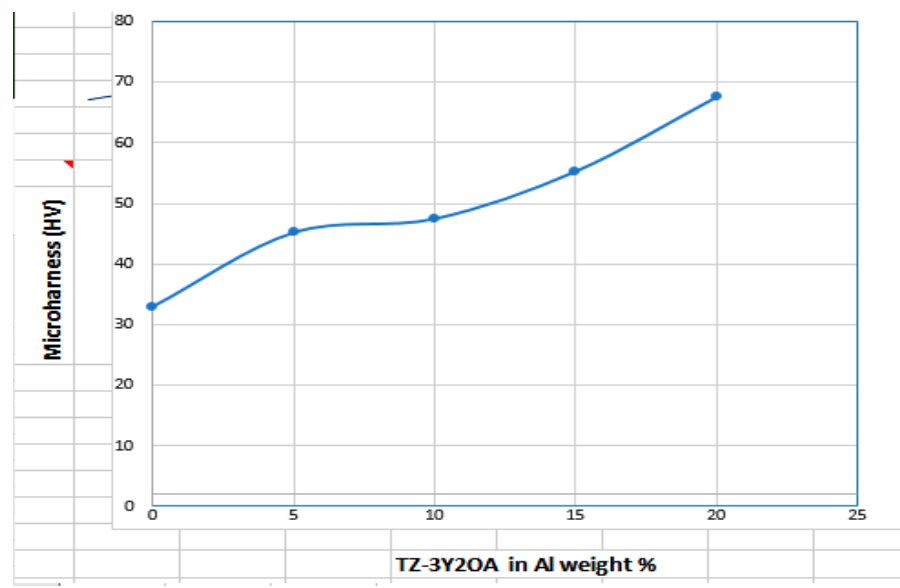

Fig. (10): Micro-hardness as a function of the TZ-3Y20A content in the AI/TZ-3Y20A compacts 


\subsection{Fracture surface:}

Figure (11) (a-e) shows the SEM fractographs of the tensile fractured surface. Fig. (10-a) shows the fracture of pure Aluminium dimples and flat areas of fracture, Fig. (11-b) shows the fracture surface of Al-5\%TZ3Y20A composite, dimples and areas are also observed. Fig. (11-c) shows the fracture surface of Al-10\%TZ$3 \mathrm{Y} 20 \mathrm{~A}$, it is a ductile fracture containing flat areas and

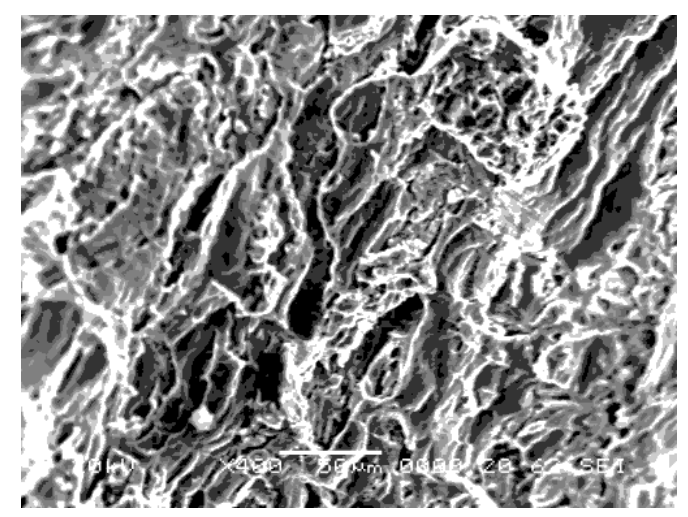

a) Pure Al sample

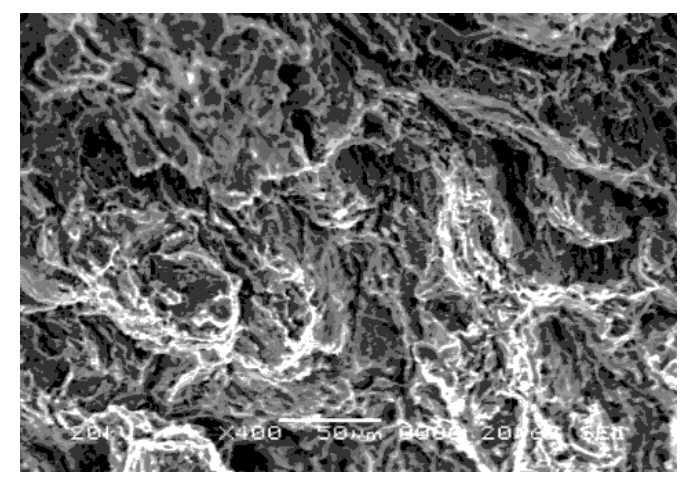

c) $\mathrm{Al}-10 \% \mathrm{TZ}-3 \mathrm{Y} 20 \mathrm{~A}$ few cavities containing particles. Fig. (11-d) shows the fracture surface of $\mathrm{Al}-15 \% \mathrm{TZ}-3 \mathrm{Y} 20 \mathrm{~A}$, it is a ductile fracture with cavities aroundTZ-3Y20A particles. Fig. (11-e) shows the fracture surface of Al-20\%TZ-3Y20A, it is a ductile fracture with cavities containing particles. The strain percentage decreases with increasing the percentage of the particles, it was $35 \%$ in pure aluminium, it decreases to $16 \%$ in the case of $5 \% \mathrm{TZ}$ $3 \mathrm{Y} 20 \mathrm{~A}$ and to $3.7 \%$ in the case of $20 \% \mathrm{TZ}-3 \mathrm{Y} 20 \mathrm{~A}$.

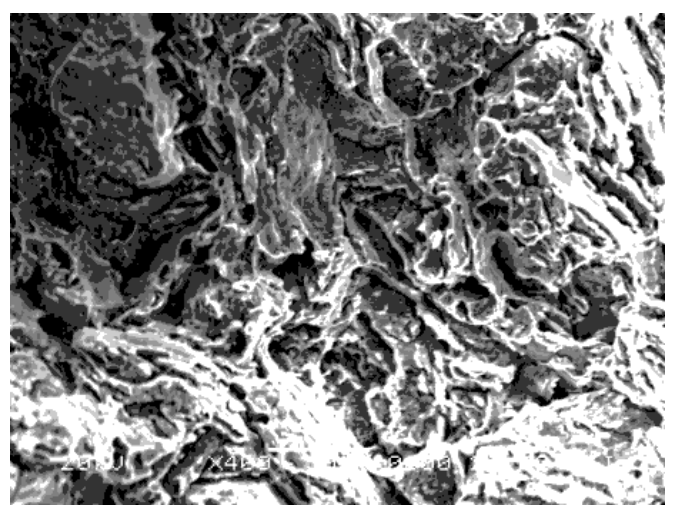

b) Al-5\% TZ-3Y20A

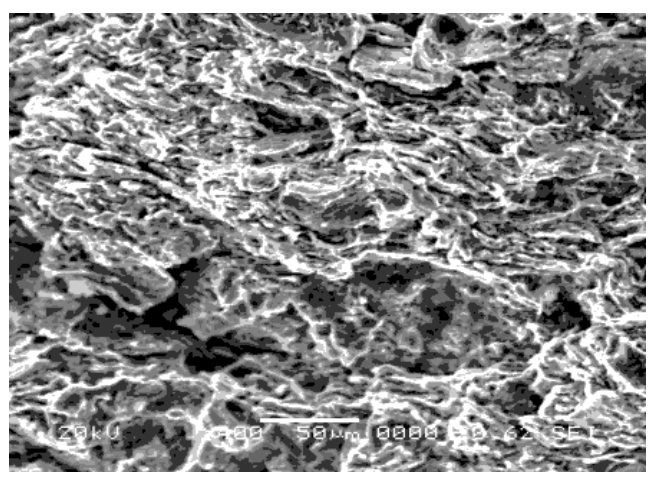

d) $\mathrm{Al}-15 \% \mathrm{TZ}-3 \mathrm{Y} 20 \mathrm{~A}$

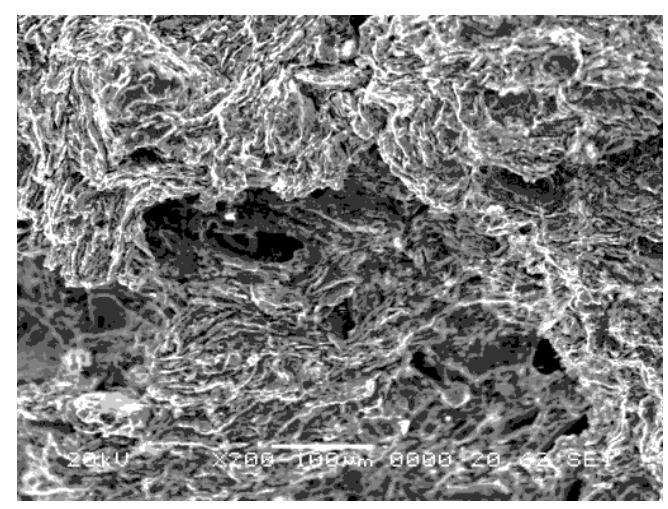

e) Al-20\% TZ-3Y20A

Fig. (11): SEM of fracture surface of AI-TZ-3Y20A composite
(a) Pure Aluminium sample
(b) $\mathrm{Al}-5 \% \mathrm{TZ}-3 \mathrm{Y} 20 \mathrm{~A}$
(c) $\mathrm{Al}-10 \% \mathrm{TZ}-3 \mathrm{Y} 20 \mathrm{~A}$
(d) $\mathrm{Al}-15 \% \mathrm{TZ}-3 \mathrm{Y} 20 \mathrm{~A}$
(e) $\mathrm{Al}-20 \% \mathrm{TZ}-3 \mathrm{Y} 20 \mathrm{~A}$ 


\subsection{Wear test}

It has been reported that the abrasive wear resistance of particle reinforced MMCs (Metal-matrix composites) increases with the volume fraction of particles, under both high and low abrasive wear conditions (12-13). The amount of wear generation depends upon the applied load, sliding speed, material properties sand environment (13). Fig. (12) shows the results of wear resistance test for Al-TZ-3Y20A composite. The test was conducted at $150 \mathrm{rpm}$ velocity, for $15 \mathrm{~min}$. at a constant load $340 \mathrm{gm}$, in air and the abrasive media was emery paper grade 600 . From Fig.(12) it is observed that as the Al-TZ-3Y20A particles percentages increase the amount of weight loss decreases. It can be attributed to the increased microhardness with increasing the weight percentage of TZ-3Y20A. The weight loss for pure Aluminium is $0.355 \mathrm{gm}$, while that for specimen with $20 \% \mathrm{TZ}-3 \mathrm{Y} 20 \mathrm{~A}$ particles is $0.157 \mathrm{gm}$.

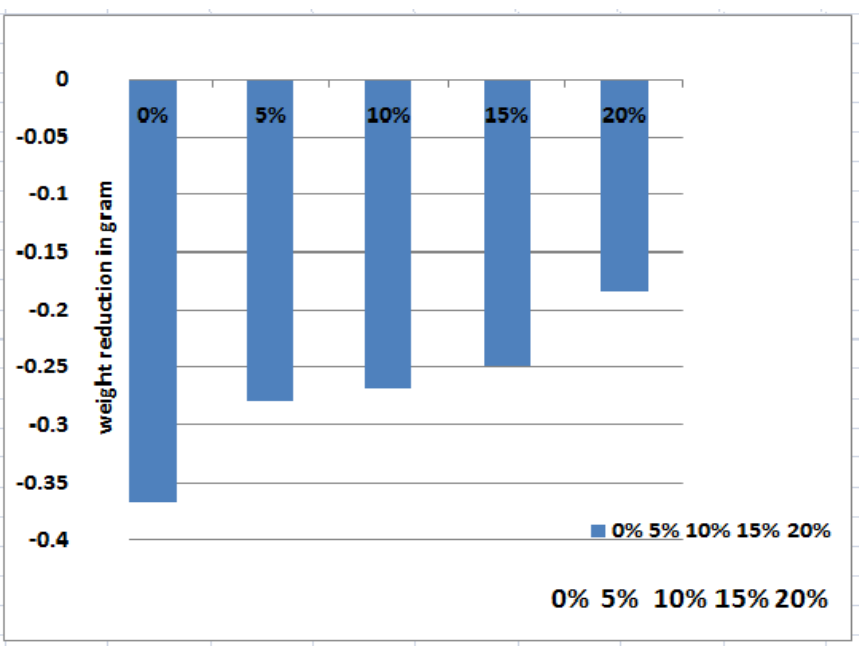

Fig. (12): Wear Test Histogram of Al-TZ-3Y20A composite at $150 \mathrm{rpm}$ for $15 \mathrm{~min}$.

\section{CONCLUSION}

This work investigates the mechanical and wears behavior of the composite materials for pure Aluminium reinforced by TZ-3Y20A particles with increasing the weight, percentage from $5 \%$ to $20 \%$. A noticeable increase in the ultimate tensile strength for $5 \% \mathrm{TZ}-3 \mathrm{Y} 20 \mathrm{~A}$ composite following by a decrease due to the increase in the TZ-3Y20A percentage. Also, the micro-hardness is increased with increasing the TZ-3Y20A particles.

Wear resistance increases by increasing the reinforced TZ-3Y20A percentage. The results indicated as the TZ3 Y20A particles percentage increase, the amount of weight loss decreases. The weight loss for pure
Aluminium is 0.355 while that for specimen with $20 \%$ TZ3 Y20A particles is 0.157 . The wear rate decreases with increasing the TZ-3Y20A particles percentage in the composites

\section{REFERENCES}

[1] S.ASajjadi, H.R.Ezalpoor, and T.ToriliParizi,"Comparison of microstructure and mechanical properties of A356 Al alloy/Al2O3 composite fabricated by stir and comprcasting process, Hoterials and Design, 34(2021) pp 106-112

[2] I.M.Hutchings, Tribological properties of metal matrix composites, Material science and Technology, 10(1994), pp 513-517

[3] A.B.Guren and T.N.Bakor, "Wear behavior of AA 6061 Aluminium alloy and its composites" wear, 188, (1995), pp185-191

[4] C.Suryanarayano, "Mechanical alloying and milling"prog.mater. Scince, (2001), 46, 1-184.

[5] HafeezAhamed,.Senthiflkumac"Experimintal investigation on newly developed Ultrafine-grained Aluminium based nano-composites" Materials and Design, 37,(2012)182-192.

[6] A.Mazahery, H.abbdizadel, H.R.Beharvandii' Development of high performance A356/A12O3 composits"Material Science and Engineering A,518(2009) pp 61-64.

[7] A.Fathy,A.Wagih, A.Abd El-Hamid, Ahmed A.Hassan"Advanced Powder Technology,25(2014)1245-1350.

[8] Dinesh Kumar lcoli, GeetaAgnihatri, Rajesh Purohite, "Properties and characterization of Al$\mathrm{A} 12 \mathrm{O} 3$ composites processe by casting and powedr Metallurgy rautis" International Journal \& latest trends in Engineering and Technology, Vol.2.1 issue 4,(2013).

[9] M.C.Watson, T.W.Cline, ActaMetall.Material, 40,(1992), 135-140.

[10] M.Kargul, I.Borowiccka, Jamrozek, M.Kanieezny,"The effect of rienforced particles size on the properties of $\mathrm{Cu}-\mathrm{Al}_{2} \mathrm{O}_{3}$ composites", Materials Science and Engineering,461,(2019)(1-6).

[11] A,Banerjee, S.V.Pasad, M.K.Surappa and P.K.Rohatgi, "Abrasive wear of coat aluminium alloy-Ziecon particle composites",Wear, 82(1982),141-151.

[12] A.B.Gurcan,T.N.Baker,"wear behaviour of AA6061 aluminium alloy and its composites", wear,188,(1995),185-191. 